\title{
Effect of Nearby Buildings on Electromagnetic Fields from Lightning
}

\author{
A. Mosaddeghi ${ }^{1}$, D. Pavanello ${ }^{1}$, F. Rachidi ${ }^{*}$, , M. Rubinstein ${ }^{2}$ and P. Zweiacker ${ }^{1}$ \\ ${ }^{1}$ Swiss Federal Institute of Technology (EPFL), EMC Group, Lausanne, Switzerland \\ ${ }^{2}$ University of Applied Sciences, IICT, Yverdon, Switzerland
}

\begin{abstract}
We present a discussion on the effect of nearby buildings on the electric and magnetic fields radiated by lightning. Electric and magnetic fields radiated from distant natural lightning have been measured simultaneously on the roof of a building (the Power Systems Laboratory of the Swiss Federal Institute of Technology, Lausanne, Switzerland) and on the ground at different distances away from it. The results suggest that the measured electric field on the roof of the 9-m tall building is enhanced by a factor of 1.7 to 1.9 , whereas the electric fields on the ground experience a significant reduction due to the shadowing effect of the building. Also, it is shown that for a sensor located on the ground, close to a building, the magnetic field component perpendicular to the building can also experience a significant attenuation, presumably due to the effect of the induced currents in the building. The results are supported by numerical simulations, obtained using NEC-4, in which the building is represented using a simple wire-grid model.
\end{abstract}

\section{INTRODUCTION}

Sensors used for the measurement of lightning electric and magnetic fields are often placed close to or on top of buildings or other structures. Metallic beams and other conducting parts in those structures may cause enhancement or attenuation effects on the measured fields [1-6]. Rubinstein et al. [1] used simultaneous measurements of lightning electric fields at the top of a building and at ground level to estimate an enhancement factor for the electric field of about 1.5 for their 17-floor building. Bonyadi-Ram et al. [2] presented a theoretical analysis in which the building on which the electric field was evaluated was represented by a metallic wire-grid model. Their results imply that the enhancement factor for the electric field is about 2.3 for a $10-\mathrm{m}$ high building and increases with the height of the structure. Bermudez et al. [4] and Pavanello et al. [5] compared electromagnetic fields associated with lightning strikes to the Toronto $\mathrm{CN}$ Tower measured on the roofs of buildings at different distances from the tower with theoretical estimations. Their results suggest that both the electric and the magnetic fields may have been enhanced by the presence of the buildings, although the degree of enhancement was actually more significant for the electric field than for the magnetic field. Baba and Rakov [6] applied the finite-difference time-domain (FDTD) method to evaluate the effect of a building on the vertical component of electric field radiated by nearby lightning. Their computation results show that the magnitude of the E-field on the roof of a $20-\mathrm{m}$ building is about 1.5 times greater than that at the same horizontal distance on the ground surface in the absence of the building.

In this paper, we present an experimental analysis for the evaluation of the distortion introduced by a building on the electric and magnetic fields from lightning. Preliminary results were already presented in [7] and [8]. A numerical

*Address correspondence to this author at the Swiss Federal Institute of Technology (EPFL), EMC Group, Lausanne, Switzerland; Tel: +41-21-693 26 20; Fax: +41-21-693 46 62; E-mail: farhad.rachidi@epfl.ch analysis using the Numerical Electromagnetics Code NEC-4 [9] is also presented to support the experimental data.

\section{CONSIDERED CONFIGURATIONS AND SIMULATION PARAMETERS}

Experimental waveforms from distant natural lightning were recorded during Summer 2006. Electric and magnetic field waveforms were measured simultaneously at two different locations, on the roof of a building (the Power Systems Laboratory of the Swiss Federal Institute of Technology, Lausanne, Switzerland) and on the ground. The building is located on the Campus of the Swiss Federal Institute of Technology in Lausanne, on the north of Lake Geneva.

The field derivatives were recorded using flat plate antennas (for the vertical $E$-field) and two magnetic loops (for the two magnetic field components $H_{\mathrm{x}}$ and $H_{\mathrm{y}}$ ) [10]. The sensors outputs were connected via 20 -m long $50 \Omega$ doubleshielded cables (RG214U type) to a digitizer.

The angle of incidence of the lightning electromagnetic field was determined using the magnetic direction finding technique [11] from the two components $H_{\mathrm{x}}$ and $\mathrm{H}_{\mathrm{y}}$ of the magnetic field measured on the roof of the building. Here we implicitly made the assumption that the magnetic field components on the roof were not affected by the presence of the building, or that both components of the $H$-field were affected equally.

Three different setups were considered and are described hereafter.

Setup 1. Fig. (1) illustrates the placement of the antennas for the first setup. The coordinate system used throughout this paper is also shown in the same figure. The sensors on the roof are located approximately 1-m away from the southern edge and equidistant from the corners, while those on the ground are located about 2 meters away from the building façade and half way along it [7]. 


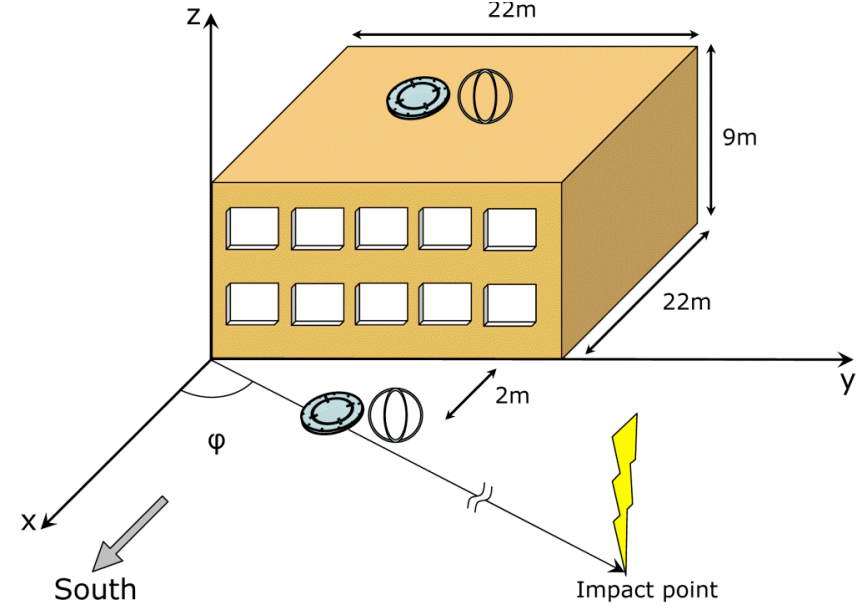

Fig. (1). Setup one.

Setup 2. Fig. (2) shows the location of the antennas for the second setup. Sets of electric and magnetic field sensors are located on the roof of the building, one in the center and the other near the southern edge ( $1 \mathrm{~m}$ away from the edge and half way along it).

(a)

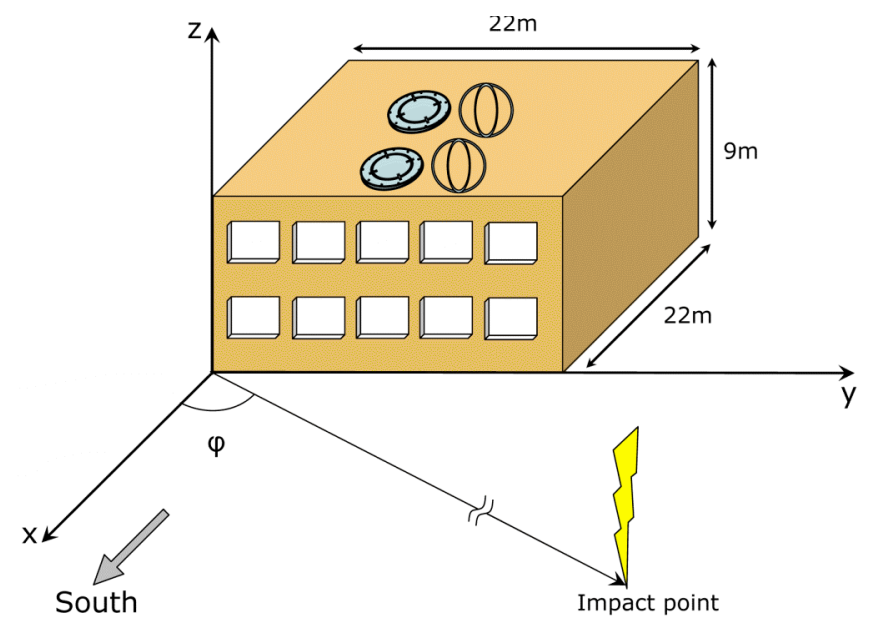

(b)

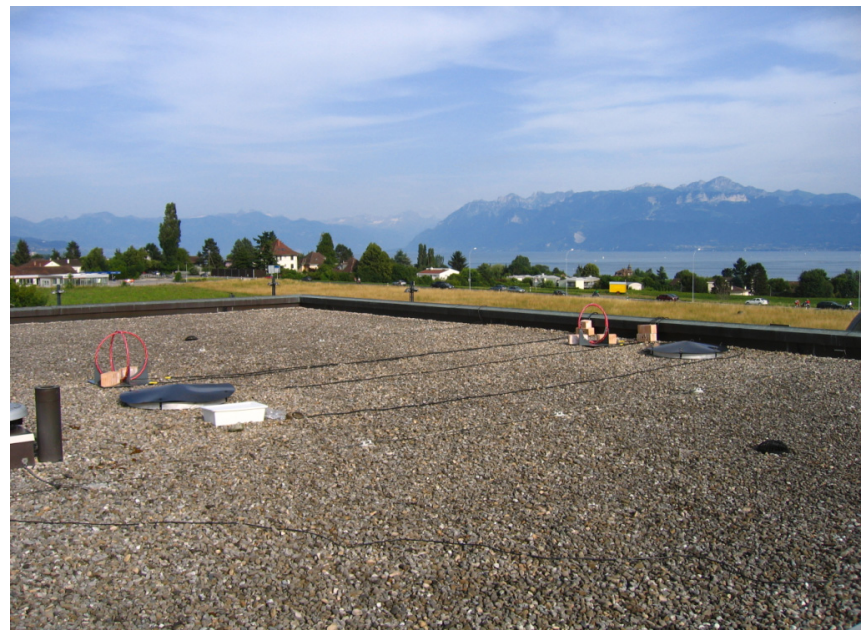

Fig. (2). Setup two (a) and location of the sensors on the rooftop (b).

Setup 3. The arrangement of the antennas used for the third setup is shown in Fig. (3). Both sets of electric field sensors are located on the ground at 2 and $7 \mathrm{~m}$ from the southern edge, as shown in the figure. The magnetic field is measured on the roof center and at $7 \mathrm{~m}$ from the southern edge.

(a)

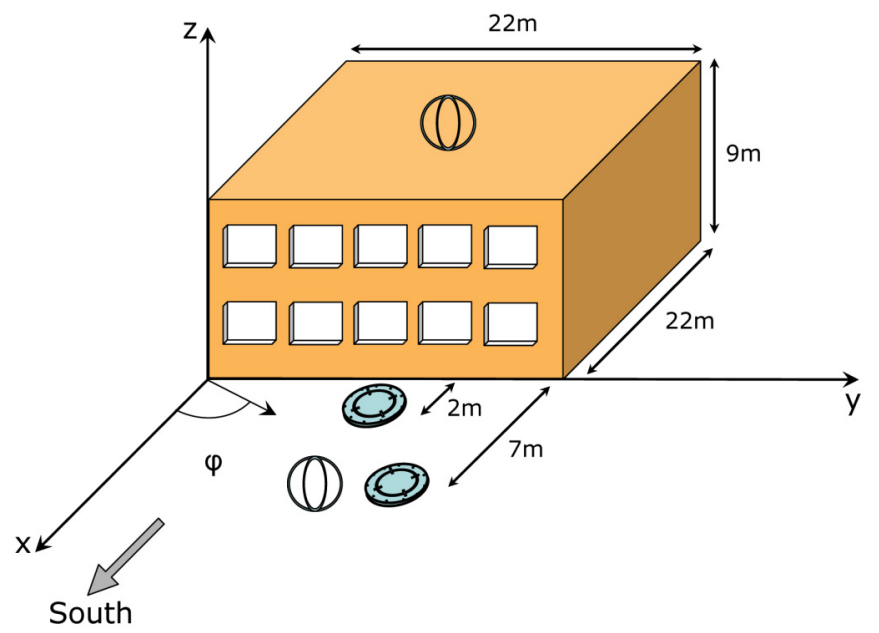

(b)

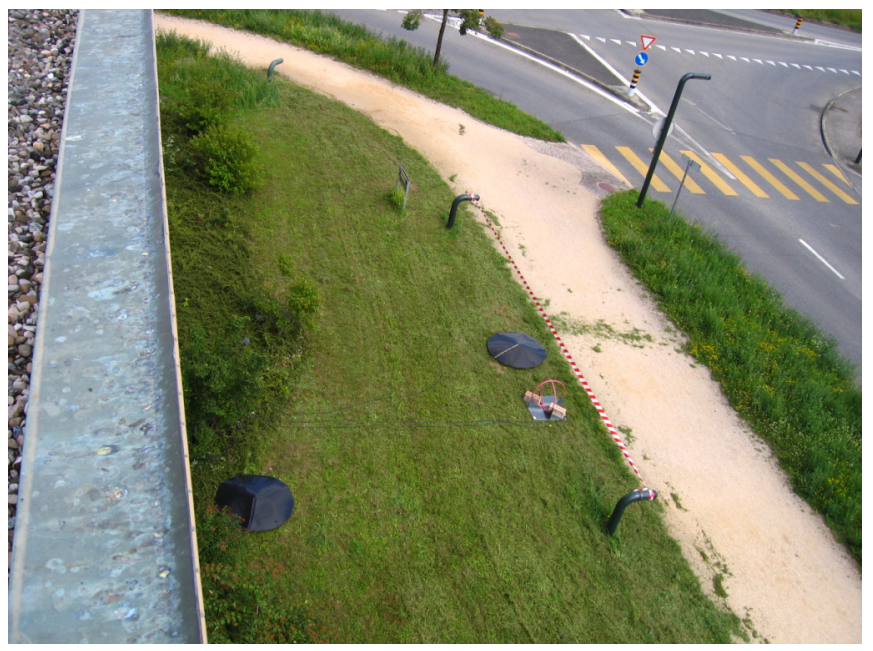

Fig. (3). Setup three (a) and location of the sensors on the ground (viewed from the rooftop) (b).

\section{EXPERIMENTAL RESULTS}

\subsection{Setup One}

We analyzed 4 flashes occurred on July 5th, 2006. These flashes were identified as negative cloud-to-ground strikes by their field signatures.

Fig. (4) presents one typical set of measurements consisting of simultaneous records of vertical electric fields and horizontal magnetic fields $\left(H_{\mathrm{x}}\right.$ and $\left.H_{\mathrm{y}}\right)$ on the roof of the building and on the ground, corresponding to a single-stroke flash occurred at 02:30:20 local time, July $5^{\text {th }} 2006$. Stepped leader pulses are clearly visible in the waveforms before the onset of the return stroke pulse. Table 1 summarizes some salient parameters (angle of incidence, field peaks) for 13 strokes out of the four flashes recorded on July 5th, 2006. Table 2 presents the ratios of electromagnetic field peaks on the roof to those measured on the ground, as well as the values for the wave impedances. 
(a)

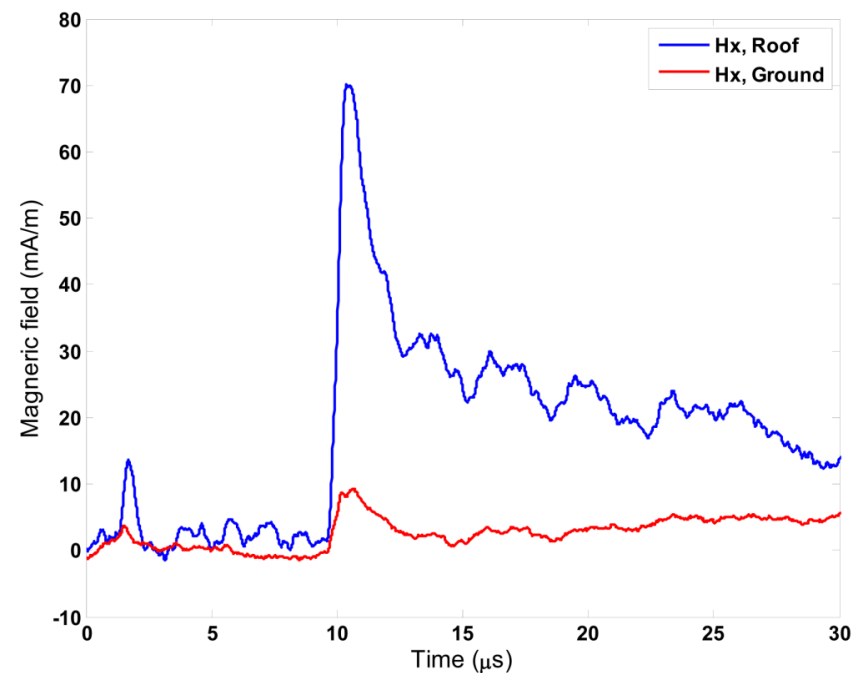

(b)

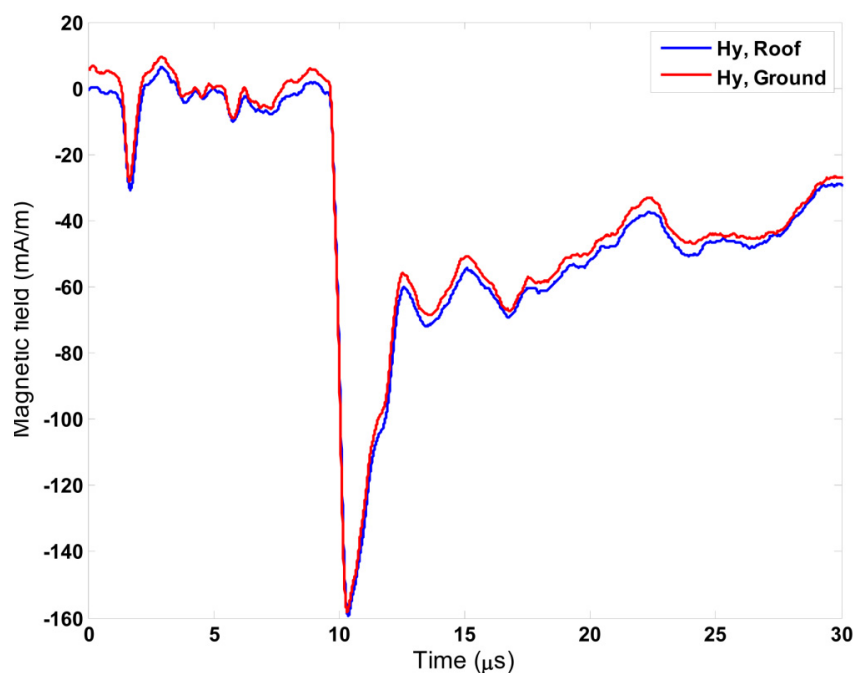

(c)

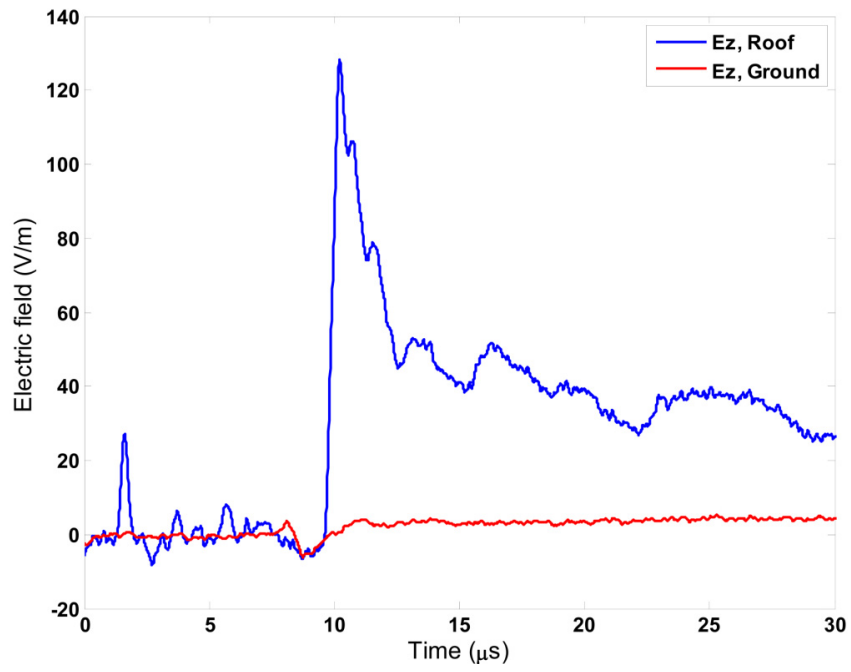

Fig. (4). Setup 1: Electric and magnetic fields recorded on July $5^{\text {th }}$ 2006, 02:30:20 local time. Single-stroke flash. Solid lines: measured waveforms on the roof, dashed line: measured waveforms on the ground. (a) $H_{\mathrm{x}}$, (b) $H_{\mathrm{y}}$, (c) $E_{\mathrm{z}}$.
It can be seen from Tables $\mathbf{1}$ and $\mathbf{2}$ that the electric field peak on the roof is one order of magnitude greater than that measured on the ground. On the other hand, the magnetic field component $H_{\mathrm{y}}$ is nearly identical on the ground and on the roof. However, the $H_{\mathrm{x}}$ component on the ground has a peak value 5 to 10 times lower than that of the same component measured on the roof.

As discussed in [7], the obtained results suggest an enhancement of the vertical electric field measured on the roof of the building, in line with the conclusions of [1-6]. The enhancement referred to in the mentioned studies is defined as the ratio of the fields on top of a building to the corresponding fields in the absence of the building. Since we measured our electric field two meters from the building, the fact that the ratio of the E-field peak on the roof to the Efield peak on the ground is about 10-30 suggests an attenuation of the E-field measured on the ground [7].

The fact that the magnetic field component at ground level perpendicular to the building façade, $H_{\mathrm{x}}$, is considerably lower than the same component on the roof is thought to be essentially due to currents induced on the metallic structure of this façade [7]. These currents flow predominantly in the yz plane and they generate therefore a magnetic field in the $\mathrm{x}$ direction.

As can be seen in the $4^{\text {th }}$ column of Table 2 , a great disparity can be observed for the ratio of the electric field on the roof and that on the ground. For example, the first flash presents ratios of $31.7,12.3,15.2$ and 26.9. Since all the measured fields for those strokes come from the same direction and propagated along the same path, they are expected to be submitted to the same attenuation and distortion effects. The fact that the ratio varies to such significant extent can be essentially due to two reasons: (1) the differences in the risetimes of the fields and possible frequency dependence of the building effect, and (2) the fact that the E-field waveforms on the ground were characterized by very low magnitudes (see Fig. $4 \mathbf{c}$ ) and hence might have been affected by noise.

In order to estimate the amount of enhancement/ attenuation of the electromagnetic field components, the following approach based on the wave impedance is proposed. Since all the events recorded in this study correspond to distant lightning strikes (some tens of kilometers), the field is essentially radiation and the electric field peak to magnetic field peak ratio should be equal to the free space wave impedance, $377 \Omega$. We also assume that the magnetic field components measured on the roof are not affected by the presence of the building. This assumption, which will be tested in Section 4, is supported by the fact that the two horizontal field components measured on the roof of the building are not expected to be significantly affected by the currents induced on the roof, which flow predominantly in the same horizontal plane. The last two columns in Table 2 present the ratio of the electric field peaks on the roof and on the ground to the magnetic field peaks on the roof. It can be seen that the ratio of the field peaks on the roof ranges from 630 to $735 \Omega$, with a mean value of $640.4 \Omega$ and a standard deviation of $10.46 \Omega$. These values indicate that the enhancement of the electric field on the roof is about 1.7 to 1.9 . The ratio of the E-field peak on 
Table 1. Setup 1: Parameters of the Events Recorded on July $5^{\text {th }} 2006$

\begin{tabular}{|c|c|c|c|c|c|c|c|c|c|}
\hline Flash & $\begin{array}{l}\text { Incidence Angle } \\
\text { (Degrees) }\end{array}$ & $\begin{array}{c}\text { Event } \\
\text { Number }\end{array}$ & $\begin{array}{c}\text { Inter-Event } \\
\text { Interval (ms) }\end{array}$ & $\begin{array}{l}E^{\text {Ground }} \\
(\mathrm{V} / \mathrm{m})\end{array}$ & $\begin{array}{c}\mathbf{E}^{\text {Roof }} \\
(\mathrm{V} / \mathbf{m})\end{array}$ & $\begin{array}{c}\mathbf{H}_{\mathrm{x}}^{\text {Ground }} \\
(\mathrm{mA} / \mathrm{m})\end{array}$ & $\begin{array}{c}\mathbf{H}_{\mathbf{x}}^{\text {Roof }} \\
(\mathbf{m A} / \mathbf{m})\end{array}$ & $\begin{array}{c}\mathbf{H}_{\mathbf{Y}}^{\text {Roof }} \\
(\mathbf{m A} / \mathbf{m})\end{array}$ & $\begin{array}{l}\mathrm{H}_{\mathrm{Y}}^{\text {Ground }} \\
(\mathrm{mA} / \mathrm{m})\end{array}$ \\
\hline \multirow{4}{*}{ July $5^{\text {th }} 2006,02: 28: 00$} & \multirow{4}{*}{63} & $1 / 5$ & & 5.8 & 183.5 & 42.5 & 247.8 & -128.8 & -136.2 \\
\hline & & $2 / 5$ & 45.6 & 4.3 & 52.7 & 11.6 & 70.1 & -35.5 & -32.7 \\
\hline & & $3 / 5$ & 67.9 & 5.9 & 90.2 & 17.6 & 122.3 & -60.9 & -62.9 \\
\hline & & $5 / 5$ & 117.9 & 2.0 & 54.6 & 14.7 & 71.3 & -35.2 & -32.7 \\
\hline July $5^{\text {th }} 2006,02: 30: 20$ & 23 & $1 / 1$ & & 3.7 & 128.1 & 9.22 & 70.1 & -159.4 & -158.1 \\
\hline \multirow{5}{*}{ July $5^{\text {th }} 2006,02: 32: 27$} & \multirow{5}{*}{60} & $1 / 5$ & & 6.5 & 125.2 & 30.5 & 180 & -66.6 & -70.8 \\
\hline & & $2 / 5$ & 66.0 & 5.4 & 101.4 & 22.1 & 148.9 & -55.8 & -58.7 \\
\hline & & $3 / 5$ & 41.3 & 4.8 & 70.8 & 17.8 & 98.4 & -36.5 & -37.3 \\
\hline & & $4 / 5$ & 50.2 & 5.1 & 67.8 & 19.5 & 100.1 & -36 & -45.6 \\
\hline & & $5 / 5$ & 52.7 & 2.4 & 35.3 & 5.42 & 51.4 & -19.2 & -19.8 \\
\hline \multirow{2}{*}{ July $5^{\text {th }} 2006,03: 07: 47$} & \multirow{2}{*}{107} & $5 / 8$ & 35.1 & 22.4 & 179.2 & 44.2 & 263 & 85.8 & 86.2 \\
\hline & & $7 / 8$ & 525.8 & 10.9 & 108.1 & 33.3 & 163.4 & 49.3 & 54.2 \\
\hline
\end{tabular}

Table 2. Setup 1: Ratios of Electric and Magnetic Field Peaks and Wave Impedances

\begin{tabular}{|c|c|c|c|c|c|c|c|c|}
\hline Flash & $\begin{array}{c}\text { Incidence Angle } \\
\text { (Degrees) }\end{array}$ & $\begin{array}{c}\text { Event } \\
\text { Number }\end{array}$ & $\frac{\mathbf{E}_{\text {Roof }}}{\mathbf{E}_{\text {Ground }}}$ & $\frac{\mathbf{H}_{\mathbf{x}}^{\text {Roof }}}{\mathbf{H}_{\mathrm{x}}^{\text {Ground }}}$ & $\frac{\mathbf{H}_{\mathbf{Y}}^{\text {Roof }}}{\mathbf{H}_{\mathbf{Y}}^{\text {Ground }}}$ & $\frac{E_{\text {Ground }}}{H_{\text {Ground }}}(\Omega)$ & $\frac{E_{\text {Roof }}}{H_{\text {Roof }}}(\Omega)$ & $\frac{E_{\text {Ground }}}{H_{\text {Roof }}}(\Omega)$ \\
\hline \multirow{2}{*}{ July $5^{\text {th }} 2006,02: 28: 00$} & \multirow{2}{*}{63} & $2 / 5$ & 12.3 & 6.0 & 1.1 & 123.9 & 670.7 & 54.7 \\
\hline & & $3 / 5$ & 15.2 & 7.0 & 1.0 & 90.8 & 660.2 & 43.4 \\
\hline July $5^{\text {th }} 2006,02: 30: 20$ & 23 & $1 / 1$ & 34.7 & 7.6 & 1.0 & 23.3 & 735.6 & 21.2 \\
\hline \multirow[b]{3}{*}{ July $5^{\text {th }} 2006,02: 32: 27$} & \multirow[b]{3}{*}{60} & $1 / 5$ & 19.1 & 5.9 & 0.9 & 84.8 & 652.3 & 34.1 \\
\hline & & $2 / 5$ & 18.7 & 6.7 & 0.9 & 86.6 & 637.7 & 34.1 \\
\hline & & $3 / 5$ & 14.9 & 5.5 & 1.0 & 114.9 & 675 & 45.2 \\
\hline July $5^{\text {th }} 2006,03: 07: 47$ & 107 & $7 / 8$ & 9.9 & 4.9 & 0.9 & 170.9 & 633.0 & 63.7 \\
\hline
\end{tabular}

the ground to the E-field peak on the roof (last column of Table 2) ranges from $20 \Omega$ to $80 \Omega$. Comparing these values to the free-space wave impedance suggests that the reduction of the electric field at ground ranges from 5 to 20 .

\subsection{Setup Two}

We analyzed 10 flashes occurred on June 20 and 21, 2006. All these flashes were identified as negative cloud-toground strikes by their field signatures.

Fig. (5) presents one typical set of measurements consisting of simultaneous records of electric and magnetic fields recorded on July $20^{\text {th }} 2006$. Table 3 summarizes parameters for 12 strokes out of the recorded 10 flashes. It can be seen that the vertical electric field at the edge of the rooftop is only slightly enhanced compared to the same component measured on the roof center (average: 5.67\%). No significant difference was found between the $y$ component of the magnetic field at the two locations. However, the magnetic field $x$-component on the edge was significantly larger than that of the center (average $29.75 \%$ ).

Table 4 presents the ratios of electromagnetic field peaks on the roof to those measured on the ground, as well as the values for the wave impedances. Assuming again that the magnetic field components measured on the roof center are not affected by the presence of the building, the enhancement of the electric field can be evaluated by 
(a)

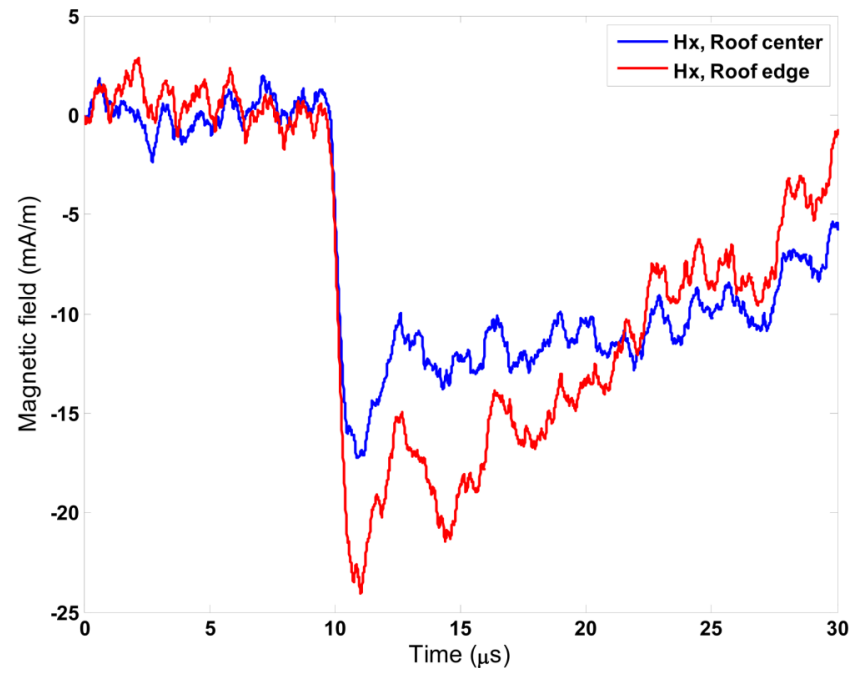

(b)

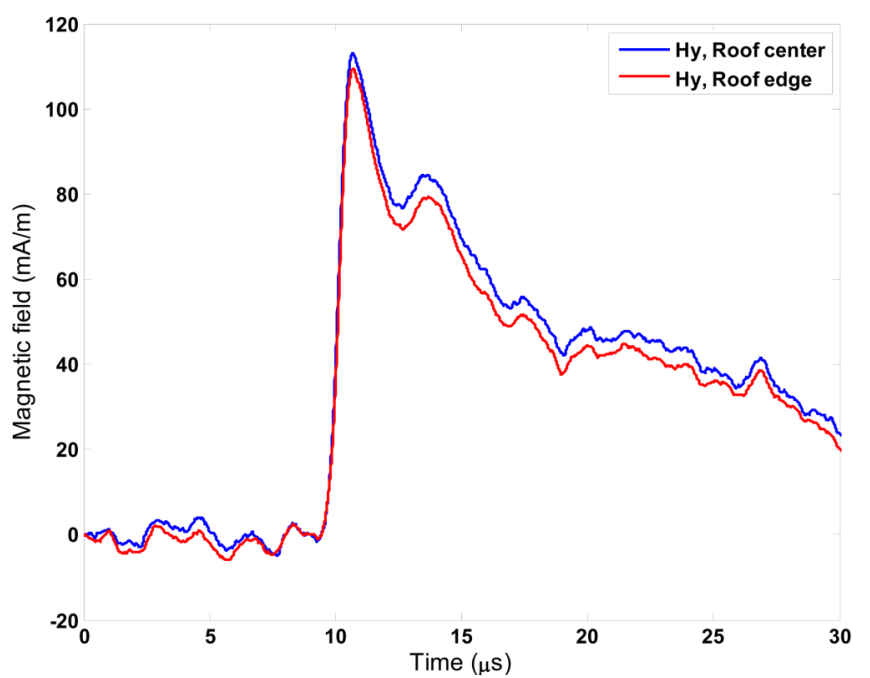

(c)

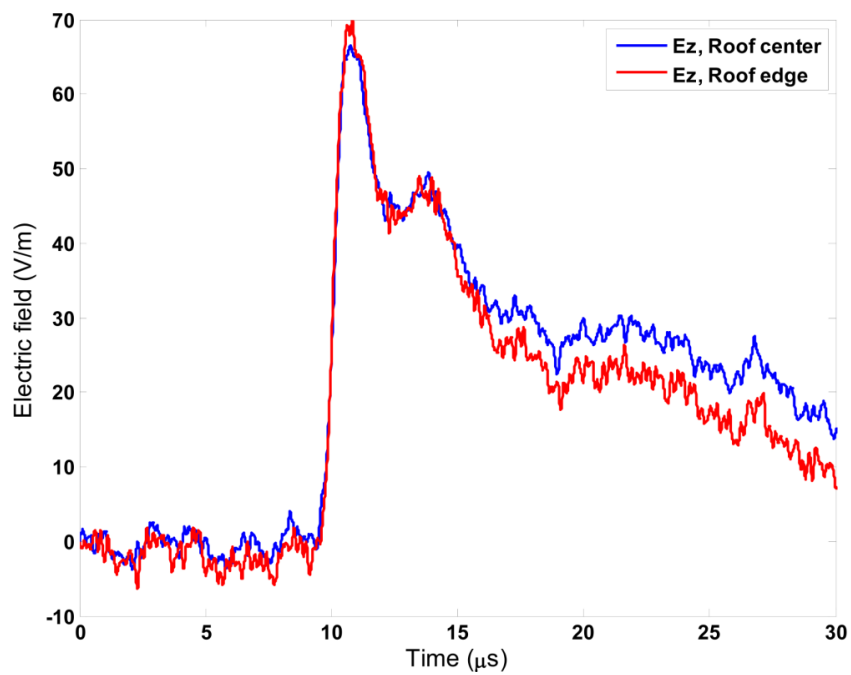

Fig. (5). Setup 2: Electric and magnetic fields recorded on July $20^{\text {th }}$ 2006, 22:50:20 local time. Stroke (3/5). Solid lines: measured waveforms on the roof, dashed line: measured waveforms on the ground. (a) $H_{\mathrm{x}}$, (b) $H_{\mathrm{y}}$, (c) $E_{\mathrm{z}}$. (a)

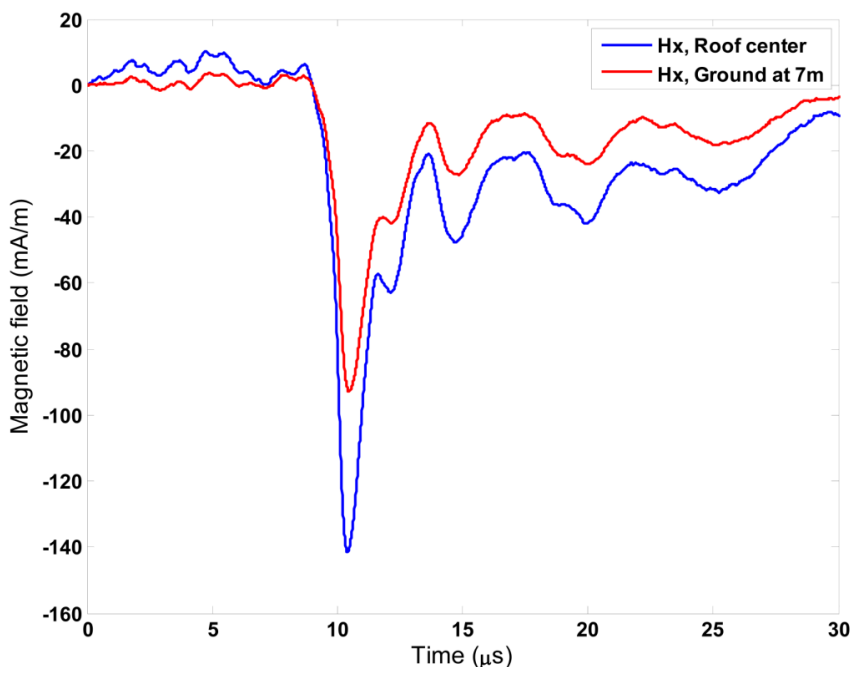

(b)

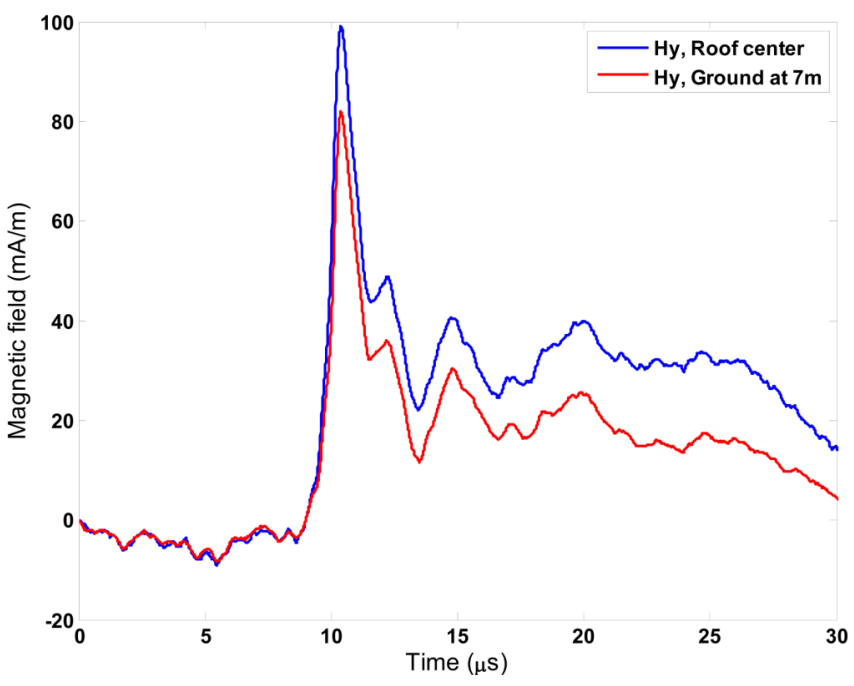

(c)

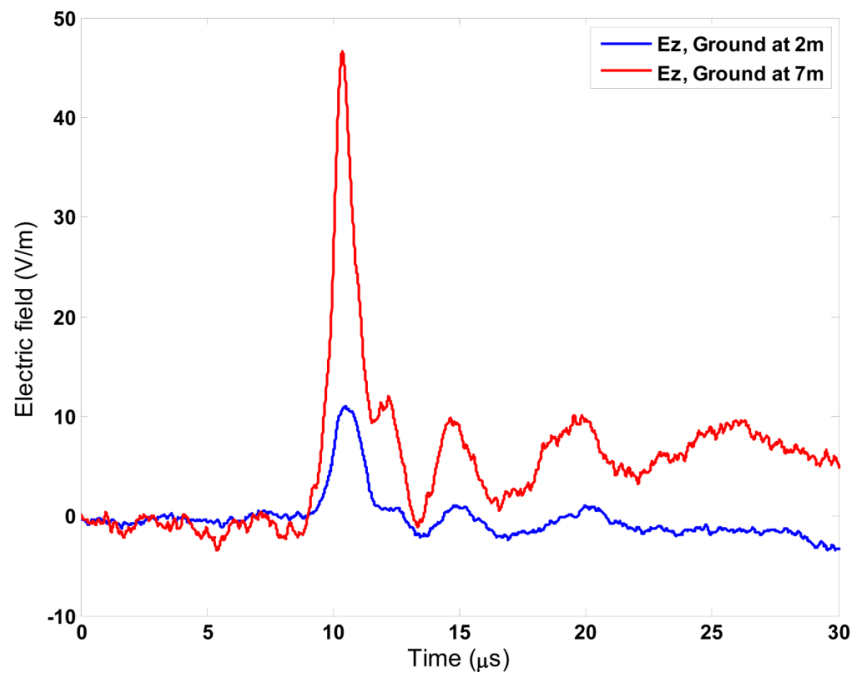

Fig. (6). Setup 3: Electric and magnetic fields recorded on July $1^{\text {st }}$ 2006, 17:15:06 local time. Stroke (3/3). Solid lines: measured waveforms on the roof, dashed line: measured waveforms on the ground. (a) $H_{\mathrm{x}}$, (b) $H_{\mathrm{y}}$, (c) $E_{\mathrm{z}}$. 
Table 3. Setup 2: Parameters of the Events Recorded on June $20^{\text {th }}$ and $21^{\text {st }} 2006$

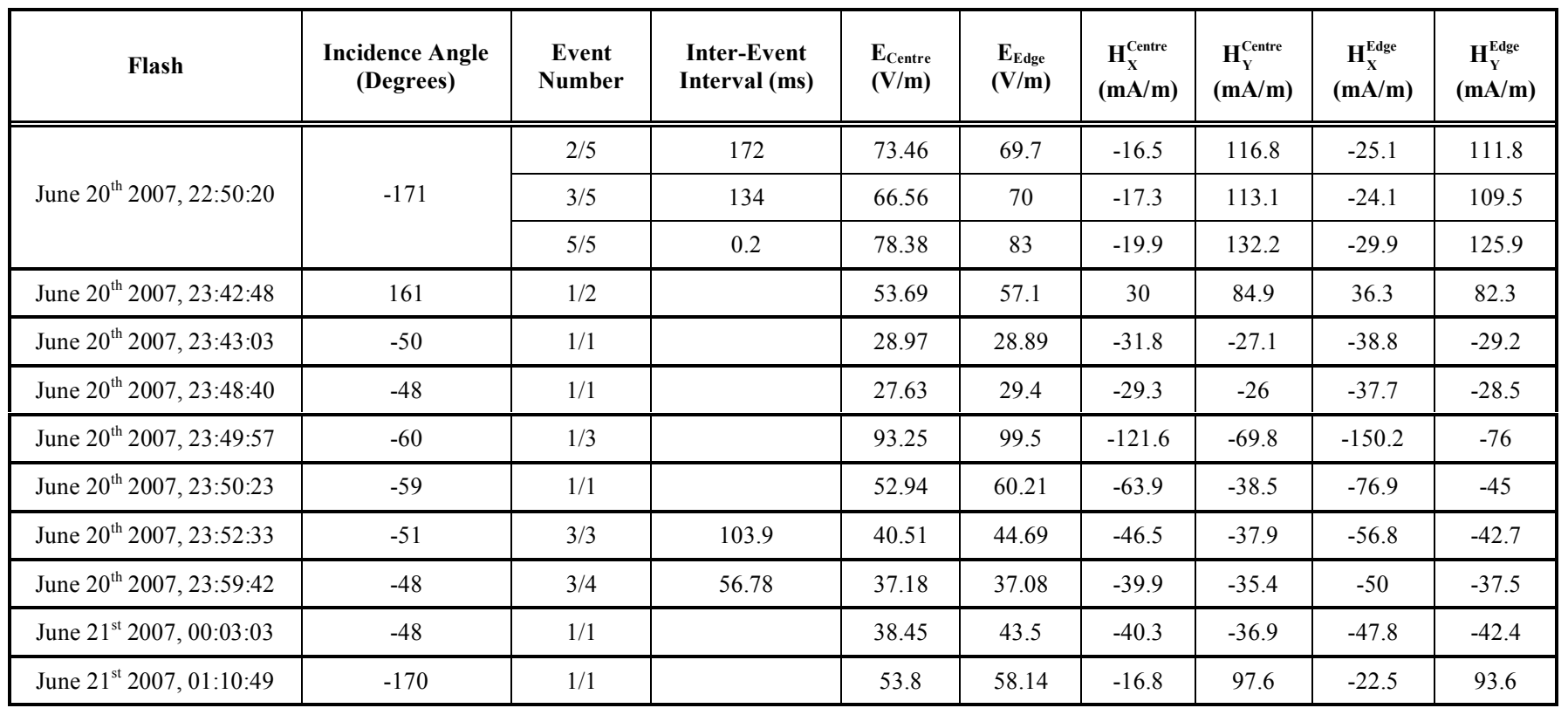

Table 4. Setup 2: Ratios of Electric and Magnetic Field Peaks and Wave Impedances

\begin{tabular}{|c|c|c|c|c|c|c|c|}
\hline Flash & $\begin{array}{l}\text { Incidence Angle } \\
\text { (Degrees) }\end{array}$ & $\begin{array}{c}\text { Event } \\
\text { Number }\end{array}$ & $\frac{\mathbf{E}_{\text {Edge }}}{\mathbf{E}_{\text {Centre }}}$ & $\frac{\mathbf{H}_{\mathrm{X}}^{\text {Edge }}}{\mathbf{H}_{\mathrm{X}}^{\text {Centre }}}$ & $\frac{\mathbf{H}_{\mathbf{Y}}^{\text {Edge }}}{\mathbf{H}_{\mathbf{Y}}^{\text {Centre }}}$ & $\begin{array}{c}\frac{\mathbf{E}^{\text {Centre }}}{\mathbf{H}^{\text {Centre }}} \\
(\Omega)\end{array}$ & 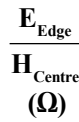 \\
\hline \multirow[b]{2}{*}{ June $20^{\text {th }} 2007,22: 50: 20$} & \multirow[b]{2}{*}{-171} & $2 / 5$ & 0.95 & 1.52 & 0.96 & 622.7 & 590.9 \\
\hline & & $3 / 5$ & 1.05 & 1.39 & 0.97 & 581.7 & 611.8 \\
\hline June $20^{\text {th }} 2007,23: 43: 03$ & -50 & $1 / 1$ & 0.99 & 1.22 & 1.08 & 693.4 & 691.5 \\
\hline June $20^{\text {th }} 2007,23: 48: 40$ & -48 & $1 / 1$ & 1.06 & 1.29 & 1.1 & 705.3 & 750.5 \\
\hline June $20^{\text {th }} 2007,23: 49: 57$ & -60 & $1 / 3$ & 1.07 & 1.24 & 1.09 & 665.1 & 709.6 \\
\hline June $21^{\text {st }} 2007,00: 03: 03$ & -48 & $1 / 1$ & 1.13 & 1.19 & 1.15 & 703.7 & 796.1 \\
\hline June $21^{\text {st }} 2007,01: 10: 49$ & -170 & $1 / 1$ & 1.08 & 1.34 & 0.96 & 543.2 & 587.1 \\
\hline
\end{tabular}

examining the last two columns in Table 4 which present the ratio of the electric field peaks on the roof center and on the roof edge to the magnetic field peaks on the roof center. It can be seen that the ratio of the field peaks on the roof ranges from 590 to $807 \Omega$, with a mean value of $686.64 \Omega$ and a standard deviation of $77.67 \Omega$. These values indicate that the enhancement of the electric field on the roof is about 1.5 to 2 .

\subsection{Setup Three}

We measured 1 flash occurred on July 1st, 2006 for this configuration and which was identified as a negative cloudto-ground strike by its field signatures.
Fig. (6) presents one typical set of measurements consisting of simultaneous records of electric and magnetic fields recorded on July $20^{\text {th }} 2006$. Table 5 summarizes parameters for the 2 strokes out of the recorded flash. It can be seen that the vertical electric field at $2 \mathrm{~m}$ from the building is significantly smaller in magnitude than that measured at $7 \mathrm{~m}$ from the building, presumably less affected by the building shadowing effect. In agreement with the results obtained for the setup 1, the magnetic field $x$-component at ground level perpendicular to the building façade, $H_{\mathrm{x}}$, is considerably lower than the same component on the roof. However, it is found for this configuration that the $H_{\mathrm{y}}$ 
component at ground level is also lower (to a lesser degree) compared to the same component measured on the roof.

Table 6 presents the ratios of electromagnetic field peaks, as well as the values for the wave impedances. It can be seen that the wave impedance for the field measured at $7 \mathrm{~m}$ from the building façade is nearly equal to the free space wave impedance. This could be considered as an indication that at this location, electric and magnetic field components are very little affected by the building. On the other hand, the ratios of the electric field at $7 \mathrm{~m}$ from the building to the magnetic field on the roof center are 261.9 and $269.7 \Omega$ for first and second stroke respectively. Assuming that the magnetic field on the roof center is unaffected by the building, this would indicate that both the electric and magnetic fields at $7 \mathrm{~m}$ from the building façade are still affected by the shadowing effect, despite the fact that their ratio is close to the free space wave impedance.

\section{SIMULATIONS}

In the analysis presented in this section, use is made of the Numerical Electromagnetics Code NEC-4 [9], a wellknown and widely used computer code based on the Method of Moments for analyzing the electromagnetic response of antennas and scatterers. The building was represented using a very simplified wiregrid parallelepiped structure consisting of 12 wires (see Fig. 7). Each wire was subdivided into 10 segments and the radius of all wires was $5 \mathrm{~cm}$. The incident field used was a plane wave with a waveshape typical of a lightning return-stroke far field and with an angle of incidence corresponding to the event presented in Fig. (4) (July $5^{\text {th }}$ 2006, 02:30:20), which corresponds to the setup 1 .

The resulting computed electric and magnetic fields are shown in Fig. (8). Table 7 presents, for comparison, the ratios of the electric and magnetic field peaks and the wave impedances determined from the measured waveforms and from the simulations. Despite noticeable differences between simulations and measurements, which are believed to be essentially due to the oversimplified model for the building, it can be seen that the computed results are qualitatively in agreement with the observed data and show the same trends.

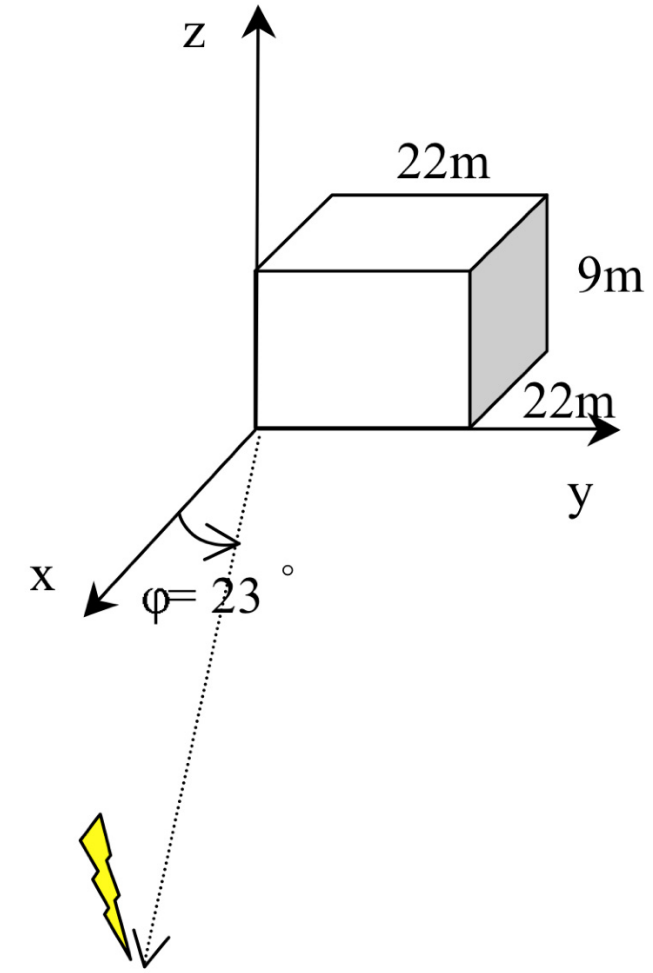

Fig. (7). Wiregrid model for the building and the configuration for the NEC-4 computation corresponding to the event recorded on July $5^{\text {th }} 2006,02: 30: 20$ local time.

Table 8 presents the difference, expressed as a percentage, between the calculated fields in the presence of the building and those obtained without the building. The results confirm (i) the enhancement of the electric field on the roof and (ii) the attenuation of the electric field on the ground. The results also confirm that the $H_{\mathrm{y}}$ component is very little affected by the building whereas the $H_{\mathrm{x}}$ component on the ground is attenuated. The results also indicate an enhancement of the $H_{\mathrm{x}}$ component on the roof, which is in agreement with the experimental results obtained for the setup 2 .

Table 5. Parameters of the Events Recorded on July 1st., 2006

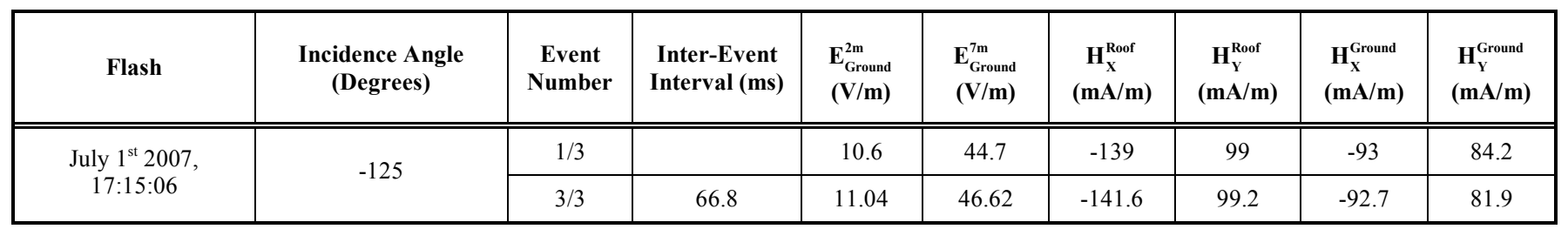

Table 6. Ratios of Electric and Magnetic Field Peaks and Wave Impedances

\begin{tabular}{|c|c|c|c|c|c|c|c|c|c|}
\hline Flash & $\begin{array}{c}\text { Incidence Angle } \\
\text { (Degrees) }\end{array}$ & $\begin{array}{c}\text { Event } \\
\text { Number }\end{array}$ & $\frac{\mathbf{E}_{\text {Ground }}^{7 \mathrm{~m}}}{\mathbf{E}_{\text {Ground }}^{2 \mathrm{~m}}}$ & $\frac{\mathbf{H}_{X}^{\text {Roof }}}{\mathbf{H}_{X}^{\text {Ground }}}$ & $\frac{\mathbf{H}_{Y}^{\text {Roof }}}{\mathbf{H}_{Y}^{\text {Ground }}}$ & $\frac{\mathbf{E}_{\text {Ground }}^{2 \mathrm{~m}}}{\mathbf{H}_{\text {Ground }}^{7 \mathrm{~m}}}$ & $\frac{E_{\text {Ground }}^{2 m}}{H_{\text {Roof }}}$ & $\begin{array}{c}\frac{\mathbf{E}_{\text {Ground }}^{7 \mathrm{~m}}}{\mathbf{H}_{\text {Ground }}^{7 \mathrm{~m}}} \\
(\Omega)\end{array}$ & $\frac{\mathbf{E}_{\text {Ground }}^{7 m}}{H_{\text {Roof }}}$ \\
\hline \multirow{2}{*}{$\begin{array}{c}\text { July } 1^{\text {st }} 2007, \\
17: 15: 06\end{array}$} & \multirow{2}{*}{-125} & $1 / 3$ & 4.22 & 1.49 & 1.17 & 78.0 & 62.1 & 356.3 & 261.9 \\
\hline & & $3 / 3$ & 4.22 & 1.53 & 1.21 & 81.3 & 63.9 & 376.9 & 269.7 \\
\hline
\end{tabular}


Table 7. Ratios of Electric and Magnetic Field Peaks and Wave Impedances. Comparison Between Measurements and Simulations. Event July $5^{\text {th }} 2006,02: 30: 20$

\begin{tabular}{|c|c|c|c|c|c|c|}
\hline July $\mathbf{5}^{\text {th }} \mathbf{2 0 0 6 , 0 2 : 3 0 : 2 0}$ & $\frac{\mathbf{E}_{\text {Roof }}}{\mathbf{E}_{\text {Ground }}}$ & $\frac{\mathbf{H}_{\mathbf{x}}^{\text {Roof }}}{\mathbf{H}_{\mathbf{x}}^{\text {Ground }}}$ & $\frac{\mathbf{H}_{\mathbf{Y}}^{\text {Roof }}}{\mathbf{H}_{\mathbf{Y}}^{\text {Ground }}}$ & $\frac{\mathbf{E}_{\text {Ground }}}{\mathbf{H}_{\text {Ground }}}(\mathbf{\Omega})$ & $\frac{\mathbf{E}_{\text {Roof }}}{\mathbf{H}_{\text {Roof }}}(\mathbf{\Omega})$ & $\frac{\mathbf{E}_{\text {Ground }}}{\mathbf{H}_{\text {Roof }}}(\mathbf{\Omega})$ \\
\hline \hline Simulation & 2.3 & 1.8 & 1.0 & 269.5 & 550.7 & 243.3 \\
\hline Measurement & 34.7 & 7.6 & 1.0 & 23.3 & 735.6 & 21.2 \\
\hline
\end{tabular}

Table 8. Percentage of Difference Between Computed Electric and Magnetic Field Components in the Presence of the Building and with the Building Removed, Leaving Only the Ground Plane

\begin{tabular}{|c|c|c|c|c|c|c|}
\hline Percentage & $\mathbf{E}_{\text {Roof }}$ & $\mathbf{E}_{\text {Ground }}$ & $\mathbf{H}_{\mathbf{x}}^{\text {Roof }}$ & $\mathbf{H}_{\mathbf{Y}}^{\text {Roof }}$ & $\mathbf{H}_{\mathbf{x}}^{\text {Ground }}$ & $\mathbf{H}_{\mathbf{Y}}^{\text {Ground }}$ \\
\hline \hline Simulation & $47 \%$ & $-35 \%$ & $27 \%$ & $-5 \%$ & $-29 \%$ & $-6 \%$ \\
\hline
\end{tabular}

(a)

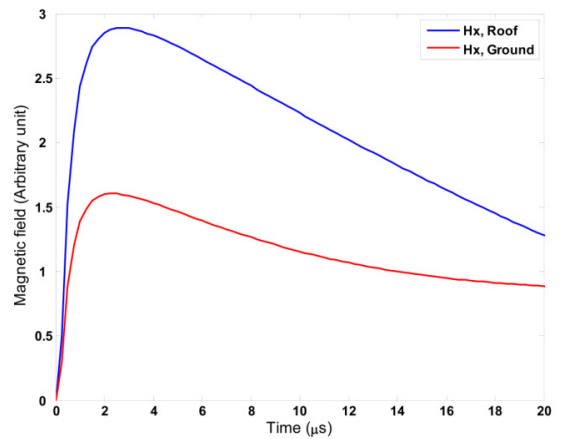

(b)

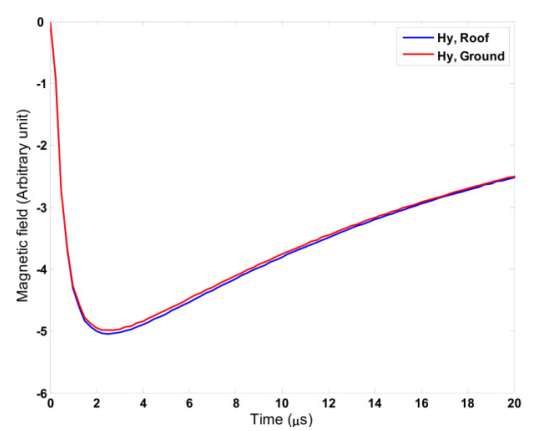

(c)

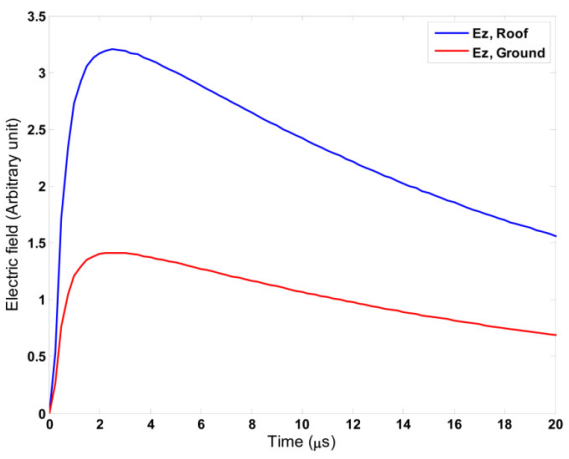

Fig. (8). Calculated electric and magnetic fields corresponding to the single-stroke flash that occurred on July $5^{\text {th }} 2006,02: 30: 20$ local time. Solid lines: calculated waveforms on the roof, dashed line: calculated waveforms on the ground. (a) $H_{\mathrm{x}}$, (b) $H_{\mathrm{y}}$, (c) $E_{\mathrm{z}}$.

\section{CONCLUSIONS}

We presented experimental waveforms radiated from distant natural lightning recorded during the Summer of 2006. Electric and magnetic field waveforms were measured simultaneously on the roof of a building (the Power Systems Laboratory of the Swiss Federal Institute of Technology, Lausanne, Switzerland) and on the ground at different distances away from it. The fields were recorded using flat plate antennas (for the E-field) and magnetic loops (for the $\mathrm{H}$-field). The results suggest that the measured electric field on the roof of the building could be enhanced by a factor of 1.7 to 1.9 , whereas the electric fields on the ground experience a significant reduction by a factor ranging from 5 to 20. Also, it is shown that for a sensor located on the ground close to a building, the magnetic field component perpendicular to the building can experience significant attenuation, presumably due to the effect of the induced currents in the building. The magnetic field on the roof of the building seems not to be significantly affected by the building.

Simulations using the Numerical Electromagnetic Code (NEC-4) were also carried out in which the building was represented using a simple wiregrid model. The simulation results support in essence the findings of the experimental analysis, despite quantitative differences which are ascribed, at least in part, to the oversimplified model of the building.

\section{ACKNOWLEDGEMENTS}

This work has been carried out within the framework of the European COST Action P18. Financial support from the Swiss Office for Education and Research SER (Project No. C07.0037) and the Swiss National Science Foundation (Project No. 200021-122457) are acknowledged.

\section{REFERENCES}

Rubinstein M, Montandon E, Ianoz M. Analysis of multi-station cloud lightning electric field pulses recorded with the swiss LPATS network. presented at 22nd ICLP (International Conference on Lightning Protection), Budapest, Hungary 1994.

[2] Bonyadi RS, Moini R, Sadeghi SHH, Mahanfar A. The effects of tall buildings on the measurement of electromagnetic fields due to lightning return strokes. presented at 2001 IEEE EMC International Symposium, Montreal, Canada 2001. 
[3] Bermudez JL, Gazizov T, Negodyaev A, et al. On the enhancement of electric and magnetic fields from lightning due to close-by metallic structures. presented at European Electromagnetics EUROEM'2004, Magdeburg, Germany 2004.

[4] Bermudez JL, Rachidi F, Janischewskyj W, et al. Far-field - current relationship based on the TL model for lightning return strokes to elevated strike objects. IEEE Trans Electromagnet Compatibility Res 2005; 47: 146-59.

[5] Pavanello D, Rachidi F, Janischewskyj W, et al. On return-stroke currents and remote electromagnetic fields associated with lightning strikes to tall structures. Part II: experiment and model validation. J Geophys Res 2007; 112: D13122.

[6] Baba Y, Rakov VA. Electromagnetic fields at the top of a tall building associated with nearby lightning return strokes. IEEE Trans Electromagnet Compatibility 2007; 49(3):632 - 43.
[7] Mosaddeghi A, Pavanello D, Rachidi F, et al. Distortion of electric and magnetic fields from lightning due to close-by metallic structures. presented at 7 th International Symposium and Exhibition on Electromagnetic Compatibility and Electromagnetic Ecology, St. Petersburg, Russia 2007.

[8] Mosaddeghi A, Pavanello D, Rachidi F, et al. An experimental analysis of the effect of nearby buildings on electromagnetic fields from lightning. presented at 29th ICLP, Uppsala, Sweden 2008.

[9] Burke GJ. Numerical electromagnetics code NEC-4 method of moments. Lawrence Livermore National Laboratory UCRL-MA1093381992.

[10] Pavanello D. Electromagnetic radiation from lightning return strokes to tall structures. Lausanne: Swiss Federal Institute of Technology (EPFL) Research 2007; Vol. 134.

[11] Rakov VA, Uman MA. Lightning: physics and effects. USA: Cambridge University Press 2003.

Received: July 14, 2009

(C) Mosaddeghi et al.; Licensee Bentham Open.

This is an open access article licensed under the terms of the Creative Commons Attribution Non-Commercial License (http: //creativecommons.org/licenses/by-nc/ 3.0/) which permits unrestricted, non-commercial use, distribution and reproduction in any medium, provided the work is properly cited. 